\title{
Thoracic endovascular aortic repair for acute complicated type B aortic dissection: Superiority relative to conventional open surgical and medical therapy
}

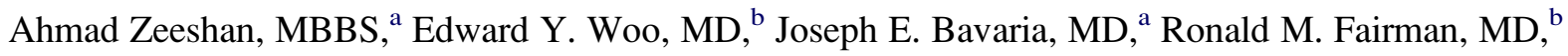 \\ Nimesh D. Desai, MD, ${ }^{a}$ Alberto Pochettino, MD, ${ }^{a}$ and Wilson Y. Szeto, MD ${ }^{a}$
}

Objective: This study compared outcomes between thoracic endovascular aortic repair and conventional open surgical and medical therapies for acute complicated type B aortic dissection.

\begin{abstract}
Methods: From 2002 to 2010, a total of 170 patients with type B aortic dissections were retrospectively identified from the University of Pennsylvania aortic database. Of these 170 patients, 147 had acute type B aortic dissections (uncomplicated 70, complicated 77). For patients with acute complicated type B aortic dissections, management included thoracic endovascular aortic repair (group A) or conventional open surgical and medical therapies (group B).

Results: In the 77 patients with acute complicated type B aortic dissections, thoracic endovascular aortic repair (group A) was performed in 45 patients $(59 \%)$. In group B, 20 patients $(26 \%)$ underwent open surgical repair and $12(15 \%)$ had their conditions managed with medical therapy. Thoracic endovascular aortic repair was associated with lower in-hospital or 30-day mortality $(\mathrm{n}=2,4 \%)$ than conventional therapy (open surgical repair $\mathrm{n}=8$, $40 \%$, medical therapy, $\mathrm{n}=4,33 \%, P=.006$ ). Patients in group A (thoracic endovascular aortic repair) continued to show significantly improved survival at 1,3 , and 5 years (group A: $82 \%, 79 \%$, and $79 \%$ vs group B: $58 \%$, $52 \%$, and $44 \%, P=.008$ ).
\end{abstract}

Conclusions: Thoracic endovascular aortic repair for acute complicated type B dissection is associated with superior early outcome and improved midterm survival relative to conventional therapy. Longer follow-up demonstrating survival benefit is needed before definitive conclusion can be made. (J Thorac Cardiovasc Surg 2010;140:S109-15)

Management of acute type $\mathrm{B}$ aortic dissection remains a clinical challenge. In acute type B aortic dissection with life-threatening complications, conventional open surgical and medical therapies continue to be associated with significant mortality risk, as high as $50 \% \cdot{ }^{1-5}$ Since its initial introduction and subsequent US Food and Drug Administration approval, thoracic endovascular aortic repair (TEVAR) has emerged as a new option for the treatment of acute type B aortic dissection. Although the role of TEVAR in the treatment of uncomplicated acute type B aortic dissection remains controversial, TEVAR has emerged as a viable option in the treatment of acute type B aortic dissection associated with life-threatening

\footnotetext{
From the Divisions of Cardiovascular Surgery ${ }^{\mathrm{a}}$ and Vascular and Endovascular Surgery, ${ }^{\mathrm{b}}$ University of Pennsylvania Medical Center, Philadelphia, Pa.

Disclosures: Joseph E. Bavaria is a member of the speakers bureau for Vascutek Terumo, and receives grant/research support from Gore \& Associates, Inc, and Medtronic, Inc, Vascular Therapy Division. Ahmad Zeeshan, Edward Y. Woo, Nimesh D. Desai, Alberto Pochettino, and Wilson Y. Szeto have nothing to disclose with regard to commercial support.

Received for publication April 28, 2010; accepted for publication June 12, 2010. Address for reprints: Wilson Y. Szeto, MD, Assistant Professor of Surgery, Surgical Director, Transcatheter Cardio-Aortic Therapies, Division of Cardiovascular Surgery, Department of Surgery, University of Pennsylvania Medical Center, Hospital of University of Pennsylvania, 3400 Spruce St, 6th Silverstein, Philadelphia, PA 19104 (E-mail: wilson.szeto@uphs.upenn.edu).

$0022-5223 / \$ 36.00$

Copyright (c) 2010 by The American Association for Thoracic Surgery doi:10.1016/j.jtcvs.2010.06.024
}

complications. Early experience has demonstrated dramatically improved perioperative results, with 30-day mortality less than $10 \%{ }^{6,7}$ Comparison with conventional open surgical and medical therapies, however, remains limited. Furthermore, data demonstrating survival benefit beyond the initial perioperative period remain lacking.

Because of the dramatic improvement in outcome in our early series, ${ }^{6}$ TEVAR has become the preferred therapy for acute type B aortic dissection with life-threatening complications at our institution. In this study, we retrospectively compared the early perioperative outcome of complicated acute type $\mathrm{B}$ aortic dissection treated with TEVAR versus conventional open surgical and medical therapies in a contemporary period. Furthermore, follow-up data were analyzed to compare survival benefit of TEVAR versus conventional surgical and medical therapies.

\section{MATERIALS AND METHODS}

A retrospective review of the thoracic aortic surgery clinical database at the University of Pennsylvania was performed from June 2002 to January 2010. Electronic and paper charts were reviewed for preoperative patient and demographic characteristics, clinical presentation, characteristics of dissection, indications for surgery, perioperative events and complications, and in-hospital mortality. Follow-up mortality data were collected by reviewing the Social Security Death Index.

From 2002 to 2010 , a total of 195 patients were admitted to our institution with the diagnosis of Stanford type B aortic dissection. In accordance 


\section{Abbreviation and Acronym \\ TEVAR $=$ thoracic endovascular aortic repair}

with the Stanford classification, type B aortic dissection was defined as any nontraumatic dissection that involved the descending thoracic aorta with the tear site distal to the left subclavian artery. Acute dissections were defined as those with delay from onset of symptoms to presentation shorter than 14 days. ${ }^{8,9}$ Diagnosis was based on history, physical examination, and imaging by echocardiography, computed tomography, or magnetic resonance imaging. Of the 195 patients identified, 147 patients had acute type B dissection. Complicated acute type B aortic dissections, as defined by the presence of rupture, malperfusion, extension of dissection, or shock, were seen in 77 patients. In this group of complicated acute type B aortic dissections, 45 patients (59\%, group A) were treated with TEVAR; the remaining 32 patients $(41 \%$, group B) were treated with conventional open surgical and medical therapies (Table 1).

The choice of therapy was made according to availability of the endografts and anatomic suitability for TEVAR. Before the US Food and Drug Administration approval of Gore TAG endoprosthesis (W.L. Gore Inc, Flagstaff, Ariz) in 2005, most patients were treated with conventional open surgical and medical therapies. After 2005, most patients, all of whom met anatomic criteria, were treated with TEVAR. Patients considered to be prohibitively high risk for open surgical repair and unsuitable for endovascular repair were treated with medical therapy alone.

The institutional review board at the University of Pennsylvania approved the study and waived the need for patient consent.

\section{Surgical Technique}

All patients underwent intervention within 14 days of initial presentation. For patients requiring conventional open surgical repair, a standard thoracoabdominal approach was used. Intraoperative neural monitoring was performed with lumbar drainage when possible. Hypothermic circulatory arrest was used when an open proximal anastomosis was necessary. Affected descending thoracic aortic segment was replaced with a Dacron polyester fabric graft. ${ }^{10}$ In a minority of cases, extra-anatomic bypasses were performed when limb malperfusion was the indication for surgical intervention.

For patients treated with TEVAR, an algorithmic approach was used, and our technique has been previously described. ${ }^{6}$ In brief, the steps of the procedure included (1) establishment of wire access in the true lumen with intravascular ultrasonographic confirmation, (2) coverage of primary tear site with endograft, (3) true lumen expansion, (4) restoration of distal aortic blood flow, and (5) correction of rupture or malperfusion with adjunct stenting.

For patients deemed at prohibitively high risk to undergo open surgical repair without anatomy suitable to TEVAR, medical therapy with strict blood pressure control and anti-impulse therapy was performed with 1 or more intravenous antihypertensive agents. Systolic and mean blood pressures were maintained below 120 and $70 \mathrm{~mm} \mathrm{Hg}$, respectively. ${ }^{11} \mathrm{~A}$ similar antihypertensive regimen was used perioperatively for all patients undergoing open or endovascular surgery. ${ }^{12}$

\section{Assessment of Aortic Remodeling, Aorta-Related Events, and Survival}

Evidence of aortic remodeling was observed by reviewing latest available post intervention computed tomographic angiography. ${ }^{13}$ Observations of the true and false lumen were made at the proximal descending thoracic aorta (at the level of the endograft) and at the distal thoracoabdominal aorta.

Patients in the TEVAR group were also followed up postoperatively to evaluate aorta-related events and survival. Aorta-related events were defined as follows: (1) aortic reintervention (open or endovascular),
(2) progression of dissection, (3) new rupture or malperfusion, (4) endoleak, and (5) aorta-related death.

\section{Statistical Analysis}

All continuous variables are expressed as mean \pm SD. Statistical methods were applied to compare group A (TEVAR) with group B (conventional open surgical and medical therapies) Univariate analysis was performed with Fisher's Exact test for categoric variables. Survival was analyzed with Kaplan-Meier survival curves. Probability values were calculated with the log-rank test. SPSS software version 15.0 (SPSS Inc, an IBM Company, Chicago, Ill) was used for all calculations.

\section{RESULTS}

In the total cohort of 77 patients with complicated acute type B aortic dissection, 45 patients underwent TEVAR (group A) and 32 patients underwent conventional surgical and medical therapies (group B). Preoperative characteristics of patients, presentation, and indications for intervention were similar between groups (Table 1).

All patients were operated on within 14 days of presentation. In group A, 26 patients $(58 \%)$ underwent TEVAR within 24 hours of presentation. In group B, 10 patients $(50 \%)$ underwent open repair within 24 hours of presentation. Aortic rupture and distal malperfusion were the major indications for operation in both groups (Table 1).

\section{Stent Grafts and Adjunct Procedures}

Three stent grafts were used for the endovascular treatment. Gore TAG thoracic endoprosthesis was used in most cases $(\mathrm{n}=37,75 \%)$. The Medtronic Talent thoracic endoprosthesis (Medtronic Vascular, Santa Clara, Calif) and the Zenith ELSE (Cook Inc, Bloomington, Ind) were each used in 4 cases $(8 \%)$.

In addition, 18 patients treated with TEVAR had 1 or more adjunct procedures performed. These adjunct procedures included distal abdominal aortic and peripheral iliofemoral stenting $(\mathrm{n}=12)$, mesenteric or renal artery stenting $(\mathrm{n}=4)$, and extra-anatomic bypass (femorofemoral bypass $\mathrm{n}=1$, left carotid-left subclavian artery bypass $\mathrm{n}=1$ ).

\section{Hospital Stay and Complications}

Although the difference was not statistically significant, TEVAR was associated with slightly shorter hospital stay than was conventional therapy (Table 2). Postoperative complications were compared between the groups (Table 2). The risk of postoperative complications was not statistically different between groups; however, of the 12 patients treated medically, $9(75 \%)$ presented with isolated renal malperfusion and subsequent renal failure. Of these 9 patients, 7 eventually either died or required long-term hemodialysis.

\section{Aortic Remodeling (Figure 1)}

Surveillance postoperative computed tomographic angiography was performed in 39 of 43 patients $(90 \%)$ who survived the perioperative period. Computed tomographic 
TABLE 1. Patient characteristics and presentation for complicated acute type $B$ aortic dissection

\begin{tabular}{|c|c|c|c|c|}
\hline & \multirow{2}{*}{$\frac{\text { Group A }(\mathrm{n}=45,59 \%)}{\text { TEVAR }}$} & \multicolumn{2}{|c|}{ Group B $(n=32,41 \%)$} & \multirow[b]{2}{*}{$P$ value* } \\
\hline & & Open surgical repair & Medical management & \\
\hline \multicolumn{5}{|l|}{ Preoperative characteristics } \\
\hline $\operatorname{Age}(y$, mean $\pm S D)$ & $59.1 \pm 13.2$ & $56.0 \pm 18.8$ & $67.4 \pm 11.7$ & .803 \\
\hline Sex (no. male) & $32(71 \%)$ & $16(80 \%)$ & $6(50 \%)$ & .544 \\
\hline Coronary artery disease & $5(11 \%)$ & $3(15 \%)$ & $5(42 \%)$ & .131 \\
\hline Myocardial infarction/angina & $4(9 \%)$ & $3(15 \%)$ & $5(42 \%)$ & .065 \\
\hline Congestive heart failure & $5(11 \%)$ & $3(15 \%)$ & $2(17 \%)$ & .733 \\
\hline Arrhythmias & $3(7 \%)$ & $3(15 \%)$ & $1(8 \%)$ & .441 \\
\hline Hypertension & $39(87 \%)$ & $11(55 \%)$ & $11(92 \%)$ & .146 \\
\hline Smoking & $21(47 \%)$ & $10(50 \%)$ & $6(50 \%)$ & .82 \\
\hline Chronic obstructive pulmonary disease & $7(16 \%)$ & $3(15 \%)$ & $4(33 \%)$ & .555 \\
\hline Cerebrovascular accident & $2(4 \%)$ & $0(0 \%)$ & $3(25 \%)$ & .644 \\
\hline Transient ischemic attack & $0(0 \%)$ & $2(10 \%)$ & $1(8 \%)$ & .068 \\
\hline Diabetes & $8(18 \%)$ & $1(5 \%)$ & $1(8 \%)$ & .18 \\
\hline Chronic renal insufficiency & $6(13 \%)$ & $3(15 \%)$ & $5(42 \%)$ & .314 \\
\hline Abdominal aortic aneurysm & $4(9 \%)$ & $3(15 \%)$ & $2(17 \%)$ & .477 \\
\hline Thoracic aortic aneurysm & $3(7 \%)$ & $2(10 \%)$ & $0(0 \%)$ & .659 \\
\hline Peripheral arterial disease & $3(7 \%)$ & $2(10 \%)$ & $2(17 \%)$ & .441 \\
\hline \multicolumn{5}{|l|}{ Presentation } \\
\hline \multicolumn{5}{|l|}{ Onset to repair } \\
\hline$<1 \mathrm{~d}$ & $26(58 \%)$ & $10(50 \%)$ & $4(33 \%)$ & \\
\hline $1-14 \mathrm{~d}$ & $19(42 \%)$ & $10(50 \%)$ & $8(67 \%)$ & \\
\hline Rupture & $17(38 \%)$ & $9(45 \%)$ & $3(25 \%)$ & 0.586 \\
\hline Malperfusion & $34(76 \%)$ & $10(50 \%)$ & $8(67 \%)$ & 0.144 \\
\hline Hypertension & $1(2 \%)$ & $2(10 \%)$ & $3(25 \%)$ & 0.405 \\
\hline Refractory pain & $4(9 \%)$ & $2(10 \%)$ & $0(0 \%)$ & 0.511 \\
\hline Retrograde extension & $1(2 \%)$ & $3(15 \%)$ & $0(0 \%)$ & .302 \\
\hline False lumen expansion & $5(11 \%)$ & $1(5 \%)$ & $1(8 \%)$ & .693 \\
\hline Shock & $2(4 \%)$ & $2(10 \%)$ & $0(0 \%)$ & .644 \\
\hline
\end{tabular}

All data are numbers and percentages of patients unless otherwise noted. TEVAR, Thoracic endovascular aortic repair. * $P$ value was calculated with Fisher's Exact test comparing group A (thoracic endovascular aortic repair) versus group B (conventional open surgical repair and medical management).

angiographic review demonstrated aortic remodeling in 30 of 39 patients $(77 \%)$ with complete thrombosis of the false lumen in the descending thoracic aorta at the level of the endograft. Complete aortic remodeling with thrombosis of false lumen of the entire thoracoabdominal aorta was seen in 11 patients $(28 \%)$. Thrombosis of false lumen at the level of the endograft with persistent false lumen patency at the level of the distal thoracoabdominal aorta was seen in 19 patients $(49 \%)$. In the remaining 9 patients $(23 \%)$, persistent patent false lumen in the entire thoracoabdominal aorta was seen.

TABLE 2. Mortality, hospital stay, and postoperative complications after thoracic endovascular aortic repair and conventional treatment

\begin{tabular}{|c|c|c|c|c|}
\hline & \multirow{2}{*}{$\begin{array}{c}\text { Group A } \\
\text { TEVAR }\end{array}$} & \multicolumn{2}{|c|}{ Group B } & \multirow[b]{2}{*}{$P$ value* } \\
\hline & & Open surgical repair & Medical management & \\
\hline \multicolumn{5}{|l|}{ Mortality and hospital stay } \\
\hline Mortality at $30 \mathrm{~d}$ & $2(4 \%)$ & $8(40 \%)$ & $4(33 \%)$ & .006 \\
\hline Hospital stay $(\mathrm{d}$, mean $\pm \mathrm{SD})$ & $15.9 \pm 11.4$ & $16.6 \pm 14.8$ & $15.9 \pm 10.2$ & .865 \\
\hline \multicolumn{5}{|l|}{ Postoperative complications } \\
\hline Cardiac complications & $3(7 \%)$ & $3(15 \%)$ & $2(17 \%)$ & .265 \\
\hline Postoperative myocardial infarction & $1(2 \%)$ & $1(5 \%)$ & $1(8 \%)$ & .373 \\
\hline Acute renal failure & $19(42 \%)$ & $4(20 \%)$ & $9(75 \%)$ & .539 \\
\hline Requirement for dialysis & $4(9 \%)$ & $3(15 \%)$ & $2(17 \%)$ & .304 \\
\hline Gut ischemia & $4(9 \%)$ & $1(5 \%)$ & $1(8 \%)$ & .621 \\
\hline Respiratory failure & $9(20 \%)$ & $2(10 \%)$ & $3(25 \%)$ & .791 \\
\hline Paraplegia & $6(13 \%)$ & $2(10 \%)$ & $1(8 \%)$ & .728 \\
\hline Stroke & $3(7 \%)$ & $0(0 \%)$ & $2(17 \%)$ & .659 \\
\hline
\end{tabular}



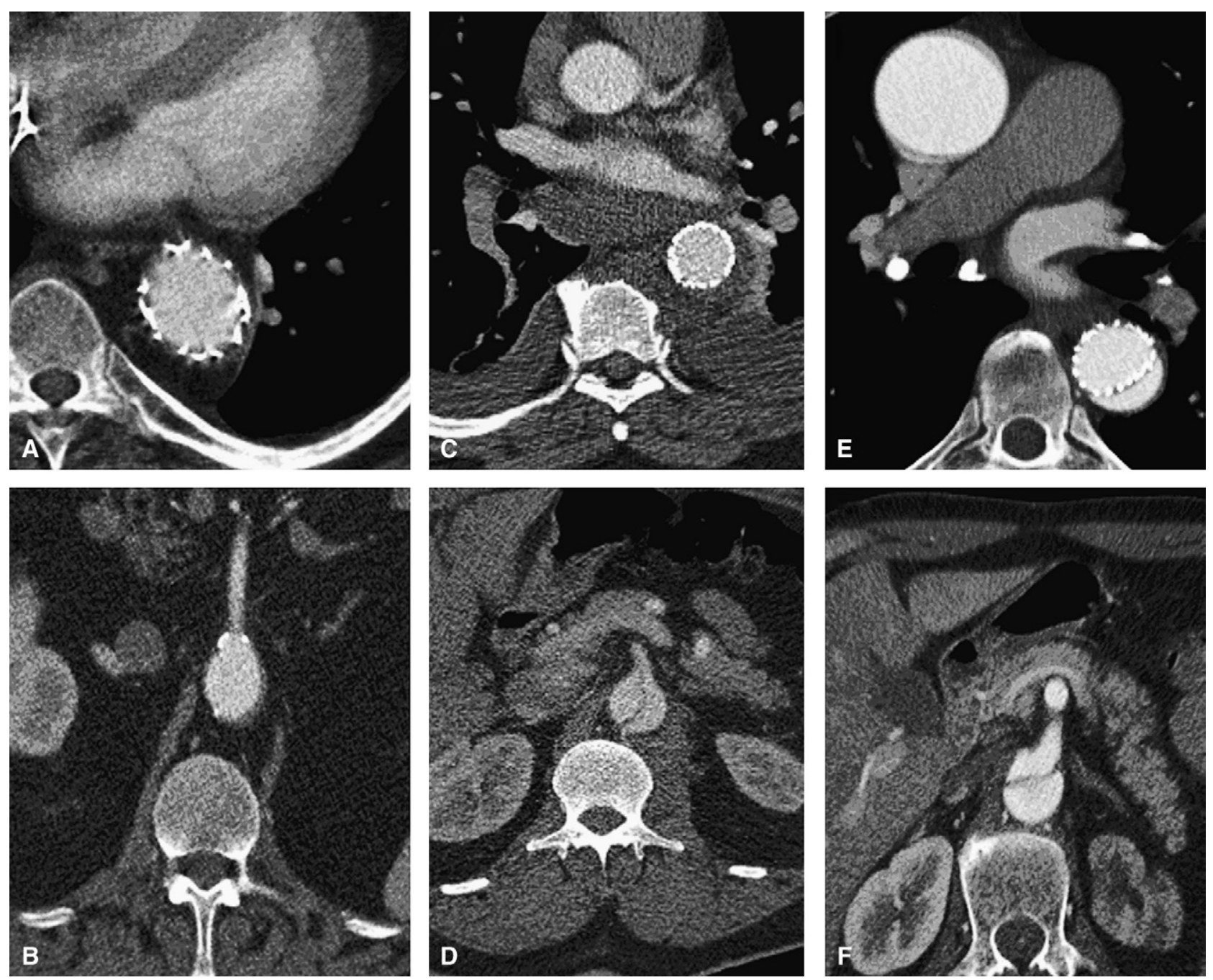

FIGURE 1. Computed tomographic angiography demonstrating complete thrombosis and obliteration of false lumen in entire thoracoabdominal aorta (A, B), thrombosis and obliteration of false lumen in thoracic aorta but patent false lumen in abdominal aorta (C, D), and patent false lumen in entire thoracoabdominal aorta (E, F).

\section{Early Outcome and Survival (Figure 2)}

The mean patient follow-up was 37 months, ranging from 2 months to 7 years. In-hospital or 30-day mortality in group A was significantly lower than that in group B $(P=.006$; Table 2). Kaplan-Meier analysis demonstrated significant improvement in survival for patients treated with TEVAR at 1,3 , and 5 years (group A $82 \%, 79 \%$, and $79 \%$ vs group B $58 \%, 52 \%$, and $44 \%$, respectively, $P=.008$ ).

In the TEVAR group, there were 2 early deaths. The first patient had a pulseless electrical activity arrest 3 days after TEVAR. The second patient had presented with left-sided stroke before TEVAR and subsequently had spinal cord ischemia after emergency TEVAR. That patient eventually died of multisystem organ failure.

In the medically managed group, there were 4 early deaths. The first patient presented with mesenteric ischemia and required a bowel resection. That patient subsequently had overwhelming sepsis with thrombocytopenia and development of multisystem organ failure. The second death was that of a patient deemed at prohibitively high risk for open surgical repair. Care was withdrawn at the family's request. The third patient was transferred to a subacute facility after initiation of medical therapy. That patient never left the medical facility, subsequently dying within 30 days of presentation. The cause of death is not available.

\section{Freedom From Aorta-Related Events}

In the TEVAR group, there were two aorta-related deaths, as described previously. Three patients had retrograde dissections develop and required open proximal aortic and arch repair. Two additional patients had rapid expansion of the proximal aorta and arch requiring ascending aortic repair including a valve-sparing reimplantation aortic root replacement. Another patient had an endoleak develop, requiring 


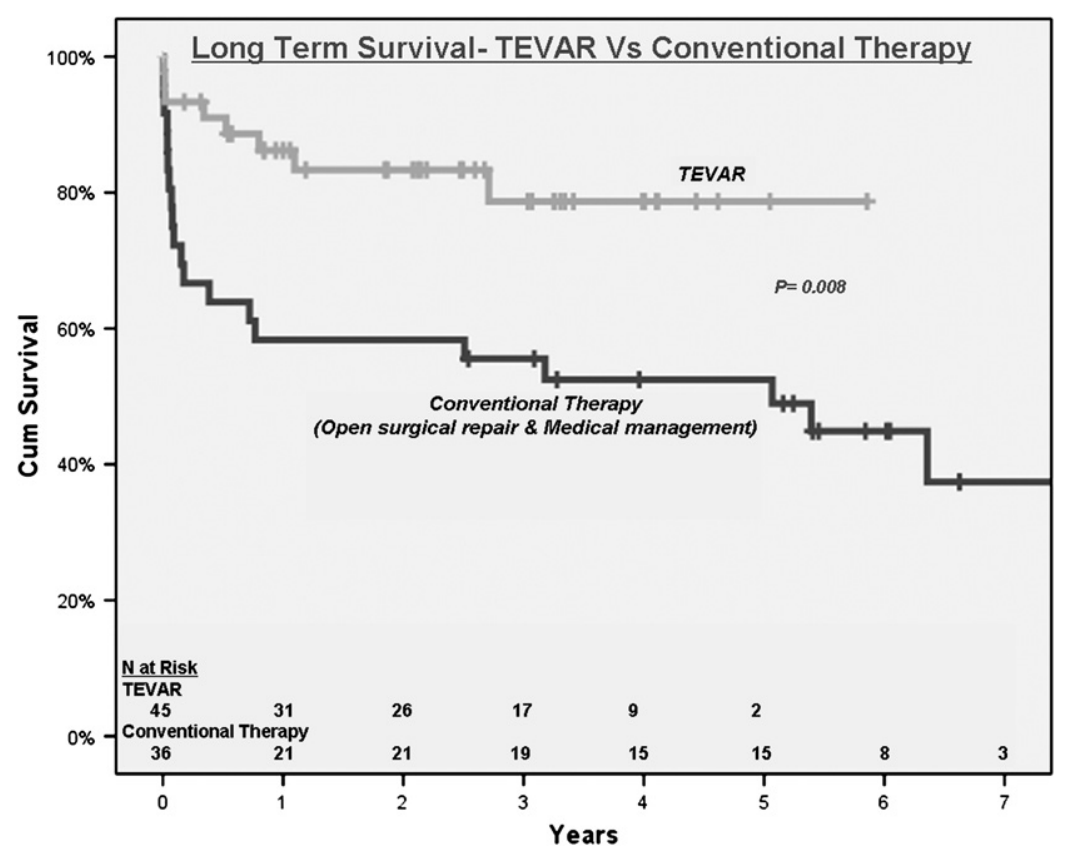

FIGURE 2. Kaplan-Meier survival curve demonstrating improved midterm survival with thoracic endovascular aortic repair (TEVAR) versus conventional open surgical and medical management (log-rank test, $P=.008)$.

endovascular reintervention. Additionally, 1 patient had thoracoabdominal aneurysmal degeneration of the distal aorta that required open repair. Another patient subsequently underwent an endovascular abdominal aortic aneurysm repair.

\section{DISCUSSION}

The treatment of complicated acute type B aortic dissection has remained a clinical challenge. Recent studies have described the safety and efficacy of endovascular repair for the treatment of complicated acute type B aortic dissection, ${ }^{6,14}$ with encouraging results in the early perioperative period; however, few studies have compared clinical outcomes between conventional open surgical and medical therapies and the use of TEVAR. In our study, the endovascular repair of complicated acute type B aortic dissection was associated with an acceptable operative mortality of $4 \%$. Furthermore, our contemporary comparison with conventional open surgical and medical therapies confirms significant improvement in patient outcome. This is not surprising in light of the high morbidity and mortality associated with conventional open and medical therapy in other series. ${ }^{1-5}$ Other centers have also demonstrated the safety and effectiveness of TEVAR for the repair of acute complicated type B aortic dissection. ${ }^{1,6,7,15,16}$ Younes and colleagues ${ }^{7}$ reported an overall 30-day mortality of 5.5\% after TEVAR. Khoynezhad and associates ${ }^{14}$ reported $82 \%$ and $78 \%$ mortalities 1 and 5 years after TEVAR. Fattori and colleagues ${ }^{1}$ reported $33.9 \%$ mortality with open surgery for acute type B aortic dissection versus $10.6 \%$ after endovascular repair. A recent meta-analysis from China reported an overall mortality of $2.6 \% \pm 0.1 \%$ after TEVAR for acute type B aortic dissection. ${ }^{17}$ These studies serve as mounting evidence that the introduction of TEVAR has resulted in a new paradigm in the treatment of complicated acute type B aortic dissection.

In our series, improvement in perioperative outcome also appears to have translated into continued improvement in midterm survival. For patients treated with TEVAR, 5 -year survival in our series remains encouraging at $79 \%$. This is consistent with a recent study reported by Khoynezhad and associates, ${ }^{14}$ which demonstrated a 5 -year survival of $78 \%$. Furthermore, in our series 5-year survival in the conventional surgical and medical therapies group is $44 \%$, which is both disappointing and significantly lower than that after TEVAR . Although our experience represents a smaller cohort, it remains consistent with larger series that used the International Registry of Acute Aortic Dissection database. ${ }^{1,5}$ These 2 larger series suggest that for complicated acute type B aortic dissection, endovascular repair is associated both with significantly improved early outcome and with midterm survival benefit at 5-year follow-up. Certainly, longer follow-up is needed before definitive conclusions can be made.

\section{Aortic Remodeling}

The concept of aortic remodeling remains debatable; however, our data do support a potential positive effect of TEVAR on aortic remodeling. Most patients treated with TEVAR ( 30 of $39,77 \%$ ) demonstrated complete thrombosis and obliteration of the false lumen in the thoracic aorta at the 
level of the endograft. Interestingly, the thrombosis rate is very similar to our experience with the use of adjunct stenting in the distal thoracic aorta during acute type A dissection repair. ${ }^{18,19}$ Most patients, however, have continued to have a patent false lumen in the distal thoracic and abdominal aorta despite complete remodeling in the proximal thoracic aorta. Whether this remodeling alters the natural history of aneurysmal degeneration of the distal thoracoabdominal aorta remains unanswered and will require longer followup. Interestingly, although it was a study examining the role of TEVAR in uncomplicated type B aortic dissection, the INvestigation of STEnt grafts in Aortic Dissection (INSTEAD) trial also demonstrated positive aortic remodeling with TEVAR, consistent with our findings. ${ }^{15}$ Although the study did not demonstrate survival benefit with TEVAR, 91.3\% patients had complete false lumen thrombosis and showed morphologic evidence of aortic remodeling. In contrast, medical treatment alone did not result in any false lumen shrinkage or thrombus formation in most cases. The lack of a survival benefit with TEVAR despite positive aortic remodeling needs further inquiry. One possible explanation is that our study is small and therefore insufficiently powered to answer this question, particularly when the control group (medical therapy for acute uncomplicated acute type B aortic dissection) has such a low mortality. Whether aortic remodeling is related or responsible for the improved midterm survival in our study will require further investigation, likely in a large, multicenter study.

\section{Off-Label Use}

Although many centers have reported the use of TEVAR in acute type B aortic dissection, we must caution that, at least in the United States, this remains an off-label use. Our institution has therefore remained cautious with the use of TEVAR in acute type B aortic dissection. In this series, only acute type $B$ aortic dissection with life-threatening complications, including malperfusion, rupture, shock, or pending rupture with rapid aneurysmal enlargement, is currently treated with TEVAR. We remain hesitant regarding the use of TEVAR in patients with stable uncomplicated acute type B aortic dissection. These presentations or clinical scenarios include refractory pain and uncontrolled hypertension in uncomplicated acute type B aortic dissection. Only for patients with factors associated with increased risk of poor outcome do we reluctantly consider treatment with TEVAR. These include increased false lumen index (false lumen $>22 \mathrm{~mm}$ ), aneurysmal characteristic with total diameter greater than $40 \mathrm{~mm}$, and an elevated fusiform index. ${ }^{20,21,22}$

\section{Limitations}

We recognize that our study has several limitations. First, it is a retrospective, nonrandomized, observational, singleinstitution study. Second, the choice of therapy was biased by the availability of endograft technology. Most patients treated with TEVAR were treated after the US Food and Drug Administration approval in 2005. Before 2005, patients were treated with open surgical therapy unless the surgeons considered the patient to be at prohibitively high risk, and endografts were available under extraordinary circumstances. Nonetheless, the open surgical cohort remains a contemporary comparative group. In addition, medical management for acute complicated type B aortic dissection was undertaken despite its known association with poor outcome from other historical studies. In our series, these patients were not treated surgically because the risk was felt to be prohibitively high. Interestingly in our small series, medical management of complicated acute type B aortic dissection was associated with a 33\% early mortality. At initial examination, our result appears relatively low compared to other historical studies; however, further examination again reveals a potential bias and perhaps a hesitancy to proceed with surgical intervention because of its association with poor outcome. In the 9 of 12 patients $(75 \%)$ with complicated acute type B aortic dissection treated medically, isolated renal malperfusion with acute renal failure was the presentation. Of these 9 patients, 7 eventually died or required long-term, chronic hemodialysis, again reflective of the poor outcome with medical management in patients with complicated acute type B aortic dissection.

\section{CONCLUSIONS}

With the introduction of TEVAR, the management of acute type B aortic dissection has evolved dramatically in the last decade. Mounting evidence is supporting the use of TEVAR, particularly for acute type B aortic dissection with life-threatening complications. Our study, a comparative study examining the treatment of complicated acute type B aortic dissection in the eras before and after the introduction of TEVAR, further strengthens the evidence for favorable outcome of TEVAR in complicated acute type $\mathrm{B}$ aortic dissection relative to the conventional treatment paradigm of open surgical and medical therapies. At our institution, we firmly believe that TEVAR has emerged as the preferred treatment strategy, representing a new surgical paradigm in the treatment of complicated acute type B aortic dissection. Furthermore, our study also suggests that the benefit is conveyed beyond the initial perioperative period, as demonstrated by significantly improved 5-year survival with evidence of aortic remodeling.

We thank Patrick Moeller and William Moser for their help with the Penn Thoracic Aortic Database and data management.

\section{References}

1. Fattori R, Tsai TT, Myrmel T, Evangelista A, Cooper JV, Trimarchi S, et al. Complicated acute type B dissection: is surgery still the best option?: a report from the International Registry of Acute Aortic Dissection. JACC Cardiovasc Interv. 2008; $1: 395-402$.

2. Bozinovski J, Coselli JS. Outcomes and survival in surgical treatment of descending thoracic aorta with acute dissection. Ann Thorac Surg. 2008;85:965-71. 
3. Crawford ES, Svensson LG, Coselli JS, Safi HJ, Hess KR. Aortic dissection and dissecting aortic aneurysms. Ann Surg. 1988;208:254-73.

4. Miller DC, Stinson EB, Oyer PE, Rossiter SJ, Reitz BA, Griepp RB, et al. Operative treatment of aortic dissections. Experience with 125 patients over a sixteen-year period. J Thorac Cardiovasc Surg. 1979;78:365-82.

5. Trimarchi S, Nienaber CA, Rampoldi V, Myrmel T, Suzuki T, Bossone E, et al. Role and results of surgery in acute type $\mathrm{B}$ aortic dissection: Insights from the International Registry of Acute Aortic Dissection (IRAD). Circulation. 2006; 114(1 Suppl):I357-64

6. Szeto WY, McGarvey M, Pochettino A, Moser GW, Hoboken A, Cornelius K, et al. Results of a new surgical paradigm: endovascular repair for acute complicated type B aortic dissection. Ann Thorac Surg. 2008;86:87-94.

7. Younes HK, Harris PW, Bismuth J, Charlton-Ouw K, Peden EK, Lumsden AB, et al. Thoracic endovascular aortic repair for type B aortic dissection. Ann Vasc Surg. 2010;24:39-43

8. Orend KH, Liewald F, Kirchdorfer B, Sunder-Plassmann L. Management of descending aortic dissection. Ann Ital Chir. 1995;66:821-4.

9. Khoynezhad A, Gupta PK, Donayre CE, White RA. Current status of endovascular management of complicated acute type B aortic dissection. Future Cardiol. 2009;5:581-8.

10. Lansman SL, Hagl C, Fink D, Galla JD, Spielvogel D, Ergin MA, et al. Acute type B aortic dissection: surgical therapy. Ann Thorac Surg. 2002;74:S1833-5; discussion S1857-63.

11. Golledge J, Eagle KA. Acute aortic dissection. Lancet. 2008;372:55-66.

12. Akin I, Kische S, Ince H, Nienaber CA. Indication, timing and results of endovascular treatment of type B dissection. Eur J Vasc Endovasc Surg. 2009;37:289-96.

13. McMahon MA, Squirrell CA. Multidetector CT of aortic dissection: a pictorial review. Radiographics. 2010;30:445-60.
14. Khoynezhad A, Donayre CE, Omari BO, Kopchok GE, Walot I, White RA Midterm results of endovascular treatment of complicated acute type B aortic dissection. J Thorac Cardiovasc Surg. 2009;138:625-31.

15. Nienaber CA, Rousseau H, Eggebrecht H, Kische S, Fattori R, Rehders TC, et al Randomized comparison of strategies for type B aortic dissection: the INvestigation of STEnt grafts in Aortic Dissection (INSTEAD) trial. Circulation. 2009;120: 2519-28.

16. Albors J, Bahamonde JA, Juez M, Alcocer J, Boix R, Rueda C, et al. Endovascular stent grafting for acute thoracic aortic pathology. J Card Surg. 2009;24:534-8.

17. Xiong J, Jiang B, Guo W, Wang SM, Tong XY. Endovascular stent graft placement in patients with type B aortic dissection: a meta-analysis in China. J Thorac Cardiovasc Surg. 2009;138:865-72.

18. Desai ND, Pochettino A. Distal aortic remodeling using endovascular repair in acute DeBakey I aortic dissection. Semin Thorac Cardiovasc Surg. 2009;21: 387-92.

19. Geirsson A, Bavaria JE, Swarr D, Keane MG, Woo YJ, Szeto WY, et al. Fate of the residual distal and proximal aorta after acute type a dissection repair using a contemporary surgical reconstruction algorithm. Ann Thorac Surg. 2007;84: 1955-64.

20. Manning BJ, Dias N, Manno M, Ohrlander T, Malina M, Sonesson B, et al. Endovascular treatment of acute complicated type B dissection: morphological changes at midterm follow-up. J Endovasc Ther. 2009;16:466-74.

21. Marui A, Mochizuki T, Koyama T, Mitsui N. Degree of fusiform dilatation of the proximal descending aorta in type B acute aortic dissection can predict late aortic events. J Thorac Cardiovasc Surg. 2007;134:1163-70.

22. Song JM, Kim SD, Kim JH, Kim MJ, Kang DH, Seo JB, et al. Long-term predictors of descending aorta aneurysmal change in patients with aortic dissection. J Am Coll Cardiol. 2007;50:799-804. 